\title{
Climate change enhances the mobilization of naturally occurring metals in high altitude environments
}

\author{
Dragos G. Zaharescu, ${ }^{1,2,3^{*}}$, Peter S. Hooda ${ }^{3}$, Carmen I. Burghelea ${ }^{1,2}$, Viktor Polyakov ${ }^{4}$, \\ Antonio Palanca-Soler ${ }^{2}$
}

${ }^{1}$ Biosphere-2, University of Arizona, Tucson, Arizona, U.S.A.

${ }^{2}$ Faculty of Biological Sciences, University of Vigo, Vigo, Spain

${ }^{3}$ School of Natural and Built Environments, Kingston University London, U.K.

${ }^{4}$ Southwest Research Center, United States Department of Agriculture, Tucson, Arizona, U.S.A.

*Corresponding author, DG Zaharescu:zaha_dragos@yahoo.com

PS Hooda: p.hooda@kingston.ac.uk

C Burghelea: bcarmen@email.arizona.edu

V Polyakov: viktor.polyakov@ars.usda.gov

A Palanca-Soler: apalanca@uvigo.es

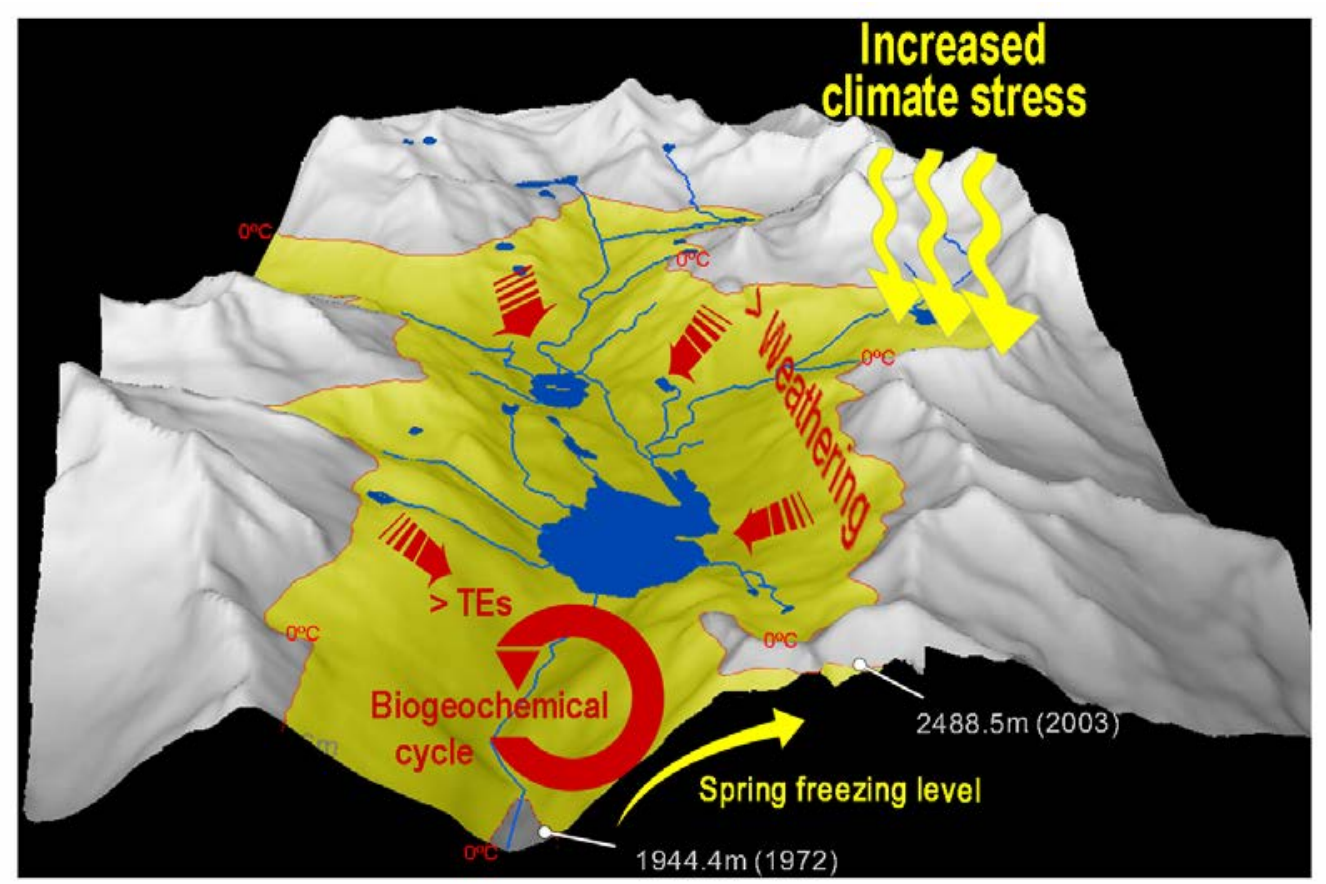

Graphical abstract: Catchment of Lake Respomuso in the central Pyrenees (Spain) experiencing increased metal mobilization due to climate change effects, including an increase in spring freezing level. 


\section{Abstract}

Manmade climate change has expressed a plethora of complex effects on Earth's biogeochemical compartments. Climate change may also affect the mobilisation of natural metal sources, with potential ecological consequences beyond mountains' geographical limits; however, this question has remained largely unexplored. We investigated this by analysing a number of key climatic factors in relationship with trace metal accumulation in the sediment core of a Pyrenean lake. The sediment metal contents showed increasing accumulation trend over time, and their levels varied in step with recent climate change. The findings further revealed that a rise in the elevation of freezing level, a general increase in the frequency of drier periods, changes in the frequency of winter freezing days and a reducing snow cover since the early 1980s, together are responsible for the observed variability and augmented accumulation of trace metals. Our results provide clear evidence of increased mobilisation of natural metal sources - an overlooked effect of climate change on the environment. With further alterations in climate equilibrium predicted over the ensuing decades, it is likely that mountain catchments in metamorphic areas may become significant sources of trace metals, with potentially harmful consequences for the wider environment.

Key Words: Climate Change, High Altitude, Trace Elements, Lakebed Sediment Record, Weathering and Transportation, Contaminant Risk

\section{Introduction}

Crossing certain boundary of climate thresholds could have serious consequences for humanity, including major changes in the Earth's other systems, such as the water and geochemical cycles (Rockström, 2009). Similar to Polar Regions, mountain-top environments are generally more sensitive to climatic change and hence are likely to experience the consequential effects first. This sensitivity comes from stronger interactions between the major circulation patterns of the atmosphere and orography, resulting in greater changes in local environment, including cloud formation and precipitation, snow/ice level, surface moisture regime, soil erosion, heat transfer on the vertical and Foehn winds (Geiger, 1965; Beniston, Diaz \& Bradley, 1997) - all these directly can influence the biogeochemical cycles (White \& Blum, 1995; Camarero et al., 2004; Piao et al., 2010). This is supported by the rise in temperature observed in mountain regions in 
recent decades, which in some places is about five-fold greater than the global warming average (Beniston, Diaz \& Bradley, 1997; Diaz \& Bradley, 1997; Nogues-Bravo et al., 2007).

In high mountain catchments the biogeochemical cycling of trace elements (TEs) is generally governed by a weathering-limited regime (Stallard \& Edmond, 1983). The geogenic inputs of TEs to mountain lakes may however be enhanced by climate change driven denudation of metal/metalloid-bearing minerals and their subsequent transport and burial in the sediments. Increased mobilization of TEs can have adverse impacts on the wider environment, including water quality (Savage et al., 2000) and human health (Charlet \& Polya, 2004). There is a considerable literature supporting increased accumulation of TEs and other contaminants in Polar and mountain regions, largely due to their long-range atmospheric transportation from anthropogenic activities (Macdonald, Harner \& Fyfe, 2005; Outridge et al., 2005; Michelutti et al., 2009; Bing et al., 2016). Also, sediment core studies have suggested changes in land use and climate during the Holocene being responsible for erosion and geochemical changes seen in lake sediments (Augustsson et al., 2013). Despite various attempts to understand the influence of climate change on mountain geochemical processes (Psenner \& Schmtdt, 1992), its potential impact on TEs release and accumulation in mountain catchments remains a major question, partly due to the complex nature of the processes involved and strong year-toyear variability. Secondly, any direct approach is not likely to provide reliable information on how weathering and transport of weathered material may have changed through time and its coupling with climate change.

Lake sediments are one of the endpoints for TEs emitted from both natural and anthropogenic sources; they can provide an accurate archive of changes in the surrounding landscapes (Yang, Graham \& Luons, 2003), including geochemical cycling of TEs. Here we present data from a Pyrenean reservoir (Lake Bubal; Figure 1), and examine the effects of changing climate patterns on TEs accumulation in a sediment profile covering $>3$ decades of historical record.

\section{Methods}

2.1 Hydrology and climate. Reservoir lakes are generally good sentinels of climate change. They can reflect changes in the catchment environment over known periods of time since their construction, usually by erecting dams (Williamson et al., 2009). Our study was conducted in Bubal lake catchment (headwaters of the River Gallego), a postglacial valley in the Central Pyrenees (42.68-42.85 N, 0.18-0.42 W, Spain; Figure 1). This catchment, of about $305.5 \mathrm{~km}^{2}$, follows a north-south orientation and is characterised by a series of interconnected lakes and typical altitude streams that drain water from the 


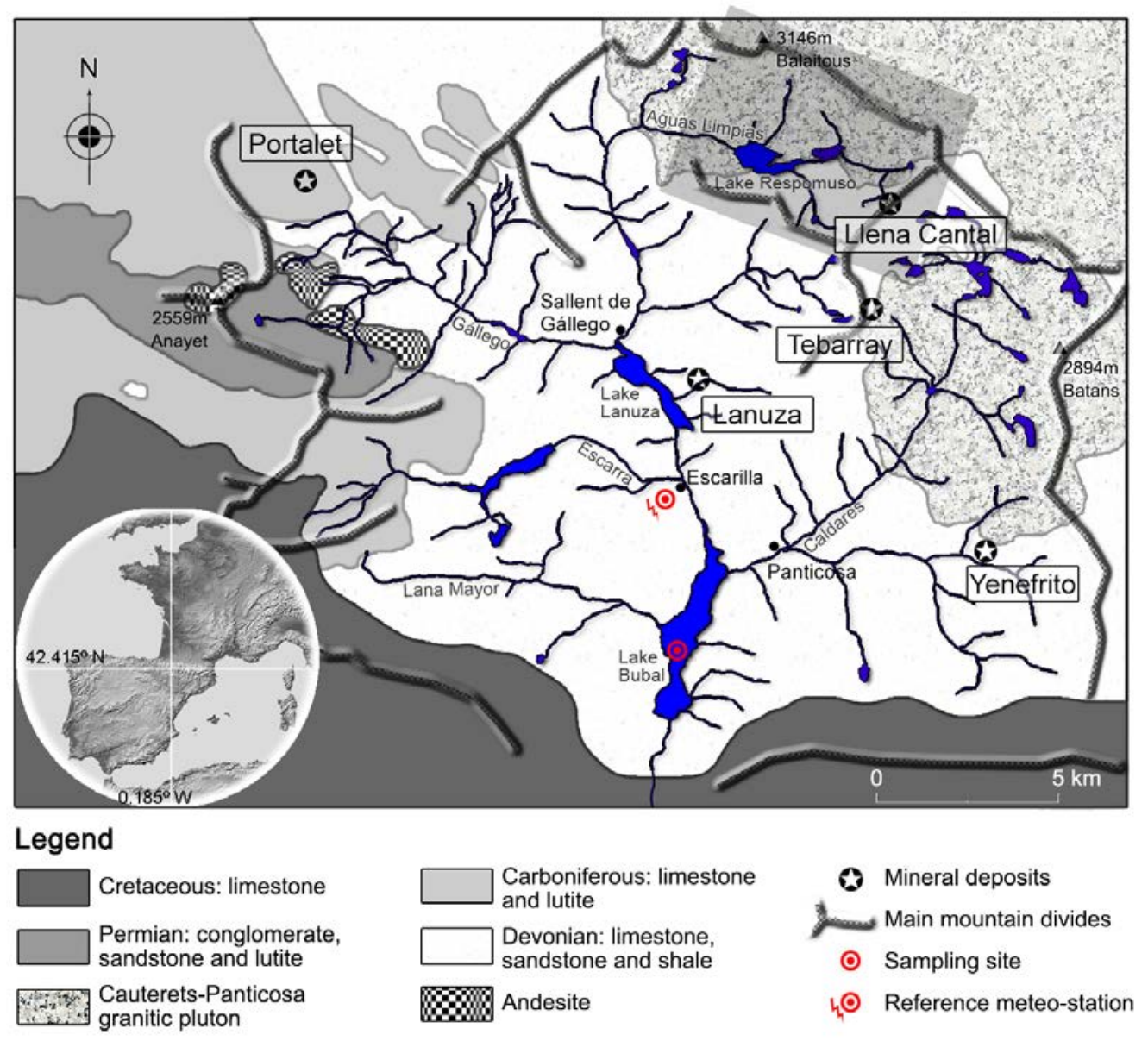

Figure 1. Hydro-geological context. Lake Bubal catchment in the Central Pyrenees with the representation of mineralization areas and sampling sites. Enclosed in a dark grey rectangle is Respomuso catchment exemplified in Fig. 5c. Map was assembled in Adobe Photoshop CS3 (https://www.adobe.com/) after Subias, Moritz \& Fernandez-Nieto (1998). Inset topography map is after NASA \& JPL (2003).

surrounding mountain slopes. Some of the lakes were transformed into reservoirs in the 1950s-60s and the main river in the catchment (Gellego) was dammed in 1971 to form Lake Bubal at $1085 \mathrm{~m}$ a.s.I., with its catchment peaks extending up to $3058 \mathrm{~m}$ a.s.l. The lake has a surface area of $234 \mathrm{ha}$, a used capacity of $64 \mathrm{hm}^{3}$ and annual water output of $382 \mathrm{hm}^{3}$ (Limnos, 1996). At about 6 water renewals each year the lake experiences a relatively short water residence time and frequent water level oscillations. Average depth of the reservoir is $27 \mathrm{~m}$, which is also the depth at the sampling location. The thermocline depth varies between 5-12 $\mathrm{m}$. All such lakes in the region have been used for both, hydroelectricity and supplying water for agriculture and potable purposes in the valley and the region further downstream. 
The long-term mean annual precipitation for the catchment is $1077 \mathrm{~mm}$ (averaged over 1972-2005). The dominant air mass direction is from W-NW bringing precipitations mainly from the Atlantic (Dessens \& Bucher, 1997). Hence, the long-distance aerial transport of contaminants must be limited in this region. This is also supported by low atmospheric deposition of metals found in the central Pyrenees at the altitude of Bubal catchment, which is considered to be similar to European background levels (BacarditPenarroya, 2011). Moreover, the bulk precipitation in the Central Pyrenees is more neutral than in other Central European sites (e.g. Alps) mainly due to lower acidic pollutant levels $\left(\mathrm{SO}_{\mathrm{x}}\right.$ and $\mathrm{NO}_{\mathrm{x}}$ ) (Camarero \& Catalan, 1993). There is also a reported decrease in acid depositions in the high Pyrenees in the last decades following the overall reductions in industrial emissions (Mosello, 2002). Therefore, the main potential source of TEs in core sediments is from the surrounding geology.

2.2 Geology. The geology of Bubal catchment is dominated by Devonian deposits (limestone, sandstone and lutite) shaped by Permian and Carboniferous materials at west and Cretaceous limestone at south (Figure 1). This geology is marked by the extrusion of Cauterets-Panticosa granitic batholith at NE which generated a low-grade contact metamorphism aureole (Subias \& Fernandez-Neto, 1995). This has significant presence of $\mathrm{W}-\mathrm{Au}$ and $\mathrm{F}-\mathrm{Zn}-\mathrm{Pb}$ vein mineralisations formed in the Devonian limestone that contain fluorite $\left(\mathrm{CaF}_{2}\right)$, sphalerite, galena $(\mathrm{PbS})$, pyrite $\left(\mathrm{FeS}_{2}\right)$, chalcopyrite $\left(\mathrm{CuFeS}_{2}\right)$, siderite $\left(\mathrm{FeCO}_{3}\right)$ and green and white fluorite (Subias, 1993). Pyrite in mineral deposits has As concentrations reaching $250 \pm 40 \mathrm{mg} \mathrm{kg}^{-1}$, while the hosting rock As content is relatively smaller and more consistent $\left(87.5 \pm 0.5 \mathrm{mg} \mathrm{kg}^{-1}\right)$ (Subias, 1993). This suggests that pyritecontaining materials (e.g. shale, schist) are potential geological source of As and other metals. Geogenic inputs of TEs have been reported in the waters and sediments of this zone, particularly in the east side (Garrido, 2002; Zaharescu et al., 2009b) (Figure 1).

2.3 Samples collection and profile characteristics. The sampling strategy covered the sedimentary record from the major catchment depository: Lake Bubal, $1085 \mathrm{~m}$ a.s.l. (Figure 1 and S1a). A $50 \mathrm{~cm}$ sediment core was extracted from the lake in bathymetric depression toward the edges of the former river $\left(42^{\circ} 41^{\prime} 49.97^{\prime \prime} \mathrm{N}, 0^{\circ} 18^{\prime} 51.65^{\prime \prime} \mathrm{W}\right.$; see Interactive Map File), where the interferences from sediment slumping or turbidity were minimal. The sampling was conducted in August 2005 when the north half of the lake bed was exposed during an unusually extreme drought. A pit was dugout in an area free of potential disturbances to extract the sediment core (Figure 1 and S1a). Therefore, no sediment compression/disturbance occurred during sampling. The cobles and forest soil at the bottom of the core clearly indicated the depth from where the new deposits were formed since 1971 when the dam was erected. The core was therefore expected to 
comprise a record from the year when this part of the river was transformed into reservoir.

The profile was brownish, indicative of oxic environment. Sediment organic content was low (3.39 $\pm 1.5 \%$, as loss-on-ignition). The profile, visually comprised of fine alluvial sediments (silt-fine sand), showed continuous record of sedimentation and no important evidence of remixing or bioturbation during the pit excavation and sampling. It is known that, in the absence of significant changes in core texture, the variation in TEs along the sediment profile can reflect the variation in their historical input (Santschi et al., 1984; Mecray et al., 2001).

The core was sectioned in the field using a wide stainless-steel spatula at $1.5 \mathrm{~cm}$ intervals. This is consistent with the averaged sediment deposition rate of $1.5 \mathrm{~cm}$ year-1 for the core extracted from upper Lake Respomuso (Lavilla et al., 2006) (Figure 1), and also with the relatively low depositional rates reported for other Pyrenean reservoirs (ValeroGarces et al., 1999). It also corresponded to the sedimentation laminae along the profile, likely produced during spring thaw, which implies sediments were not disturbed by mixing. Furthermore, sediment metal content from the present study was compared to surface sediment data collected throughout the catchment (Zaharescu et al., 2009a and Zaharescu et al., 2009b).

Climate data were provided by the Spanish National Institute of Meteorology, Madrid (INM) and covered the period 1972-2005.

2.4 Particle size distribution. Sediment samples were estimated for sand, silt and clay contents by sedimentation of a homogeneous suspension following a modification of the hydrometer method for soils (Bouyoucos, 1962). About $3 \mathrm{~g}$ air dried sample was suspended in $45 \mathrm{ml}$ dispersant solution (5\% Na-hexametaphosphate in deionised water) and shaken to separate the aggregates. Fractions (pellet) of sand and silt were collected after $40^{\prime \prime}$ and $6 \mathrm{~h} 25^{\prime}$ of settling, respectively, and the clay fraction after $15 \mathrm{~min}$ centrifugation at $3000 \mathrm{rpm}$ (1006 G-force). Sediment pellets were then oven dried at $50{ }^{\circ} \mathrm{C}$ for $24 \mathrm{~h}$ and weighted. Results were expressed in \% dry weight. Particle size distribution with depth showed a natural variability in sediment transportation and deposition with silt and clay fractions varying in step with the metals investigated (Figure S1).

2.5 Radionuclide dating. The samples were oven dried at $40{ }^{\circ} \mathrm{C}$ for 2 days, gently dispersed using ceramic pestle and mortar, sieved through $0.25 \mathrm{~mm}$ mesh size and stored in sealed plastic bags. Radioactive dating of ${ }^{137} \mathrm{Cs}$ and ${ }^{210} \mathrm{~Pb}$ followed the method described in Walling et al. (2002). The unsupported ${ }^{210} \mathrm{~Pb}$ activity vs. depth followed an exponential curve, meaning the core has little or no post-depositional disturbance(Figure S1). A peak expected for the 1986 Chernobyl incident in the stratigraphic record of ${ }^{137}$ Cs fallout was 
relatively low. Nonetheless relatively low ${ }^{137} \mathrm{Cs}$ variability with depth together with ${ }^{210} \mathrm{~Pb}$ profile support the idea that sediment supply rates to this site, although varied in granulometry, was largely constant and thus, the subsampling procedure was appropriate. The observed variability in radionuclide distribution and particle size is expected for such mountain system where climate variability such as winter catchment freezing, and other hydrological processes can slightly modify the otherwise constant input into the lake (Appleby, 2000; Kotarba, Okas \& Wachniew, 2002).

2.6 Analysis of trace and major elements, and organic matter. For TEs analysis, the < $0.25 \mathrm{~mm}$ homogenised sediment of each subsampled layer $(n=33)$ was subjected to semitotal digestion following USEPA Method 3050B for inductively coupled plasma mass spectroscopy, ICP-MS (USEPA, 1999), to extract the biologically-relevant element fraction. As, $\mathrm{Cd}, \mathrm{Co}, \mathrm{Cr}, \mathrm{Cu}, \mathrm{Mn}, \mathrm{Ni}, \mathrm{Pb}$ and $\mathrm{Zn}$ were determined by ICP-MS, using standard operating conditions and following standard QA/QC protocols. This entailed replicated certified reference materials (standard reference sediments SRM 2704, GSD-1 and GSD-4), and reagent blanks, to estimate the accuracy of the analytical method. The TEs analysis in terms of precision and accuracy was highly reliable, except for $\mathrm{Cd}$. Cadmium due to its very low level had a high relative standard deviation ( $25 \%$ ), which was considered unsatisfactory and removed from further analysis (see Supplementary Information).

Major minerogenic elements $\mathrm{Ti}, \mathrm{Fe}, \mathrm{Al}$ and Li were characterised following USEPA Method 3051A for ICP-OES (USEPA, 2007). A certified reference material from the National Water Research Institute of Canada (CRM WQB3), procedural blank and three samples were analysed in triplicate to optimize the accuracy, reproducibility and recovery rate of the extraction procedure, which were found consistent with the method used (see Supplementary Information).

Sediment organic matter content was estimated gravimetrically as loss on ignition at $550{ }^{\circ} \mathrm{C}$ for $4 \mathrm{~h}$ (Rowell, 1994).

2.7 Data analysis. First, a stepwise multiple linear regression model was fit to trace and major elements data (log-transformed) to determine the geochemical origin of TEs. Given the high correlation coefficients between TEs (Spearman rank $\rho>0.5, p<0.01$ ), and to simplify inter-elemental natural variability in relation to climate change they were summarised as regression factor scores by principal component analysis (PCA). This combined score variable is expected to offer a general response of sediment core metal content to climate variables.

Data representing average monthly temperature and precipitations at Bubal included: maximum and mean temperature, total precipitation $(\mathrm{mm})$, and the frequency of days with rain, snow, storm and freezing days. The climate was reconstructed from the 
monthly means of variables at Escarilla reference station (1170 m a.s.l.; Figure 1 and (Agustí-Panareda, Thompson \& Livingstone, 2000). The freezing level was estimated from the mean monthly air temperature at a standard adiabatic lapse rate of $0.65{ }^{\circ} \mathrm{C} 100 \mathrm{~m}^{-1}$ (Thies et al., 2007).

In the few cases where temperature values were missing in reference (Escarilla) dataset, the gaps were completed with data from the nearest neighbouring station after previously correcting for the monthly mean differences between the nearest (previous and subsequent) common years (Rosenblüth, Fuenzalida \& Aceituno, 1997; Peterson et al., 1998). Except for 6 cases (i.e. months, randomly distributed) for which the average temperature needed to be transferred from a lower station (60 km south); the stations used for correction were all in the valley, within $7 \mathrm{~km}$ of the main station. The accuracy of the method was tested using various approaches. First, a Pearson product moment correlation of the instrumental data between stations showed coefficients $>0.8$ at above 99.9 \% significance level. Subsequently, cross-validation test (Michaelson, 1987) found reasonably low errors, considering the mountain topography, of $<0.63{ }^{\circ} \mathrm{C}$ month $^{-1}$ between the obtained values and the instrumental records. Furthermore, the interpolated and the measured values were highly correlated $\left(r^{2}>0.97, p<0.01\right)$. This indicated that the method used was reliable. Precipitation variables (amount and frequency) did not require transformation as the station used for correction was within $1 \mathrm{~km}$ distance from the reference station. These calculations were performed in PASW 18 (former SPSS) for Windows.

To filter out inter-annual variability, and therefore increase the interpretability of long term behaviour of climatic factors, the variables were smoothed along time using locally estimated scatterplot smoothing (LOESS), which uses a squared polynomial function. A Gaussian smoothing parameter $(\alpha)$ of 1 was used to infer major modifications in temperature and precipitation patterns between the beginning and the end of the record period. A Gaussian filter $(\alpha=0.1)$ helped to examine the variability of TEs in step with climatic variables. The significance of the long term annual and seasonal trends in climate was tested by the nonparametric Mann-Kendall test.

To unveil the multivariate association between sediment TE contents and predictor climatic variables, we used principal component analysis (PCA). For this, the TEs (As, Co, $\mathrm{Cr}, \mathrm{Cu}, \mathrm{Mn}, \mathrm{Ni}, \mathrm{Pb}$ and $\mathrm{Zn}$ ) were summarised as standardised (centred to mean $=0$, standard deviation $=1$ ) PCA regression factor scores before using them as response variable in the model. Annual averages/sums of monthly values of climate variables were also standardised prior to using them in PCA.

Temporal variability of the TEs-climate relationships was quantified by crosscorrelation. Since autocorrelation within series prevents significance testing, a permutation test helped infer the null distribution of $95 \%$ of the cross-correlation values 
under the expectation of no correlation between any two variables of interest (Blois, McGuire \& Hadly, 2010). This was achieved by holding one variable constant, randomly rearranging the values in the second variable and recalculating the correlation coefficient. We repeated the process 1,000 times and calculated the upper and lower $2.5 \%$ cut-off values for the confidence interval. Coefficients outside the confidence interval were considered significant. Strongest correlations between climate and TEs were $r=-0.650$ and $r=0.603$ at lag $=4$ for snow days and spring freezing level, respectively (null intervals 0.320 to 0.334 , and -0.331 to 0.309 ); $r=-0.623$ at lag $=0$ for rain days (null intervals -0.347 to 0.358 ) and, $r=0.578$ and $r=-0.599$ at lag $=1$ for freezing days and storm days, respectively (null intervals -0.338 to 0.320 , and -0.347 to 0.343 ).

Variance partitioning using adjusted $r^{2}$ of linear regression (Legendre \& Legendre, 1998) helped distinguish the contribution of different sets of variables to the temporal variation of TEs while accounting for lag responses. The variables used for this analysis were standardised. Three sets of explanatory variables potentially important for metal mobilization-climate change relationship were used: (A) spring freezing level and snow days, (B) rain days and record period, and (C) freezing days and storm days. Variables within sets were also similar in their lag effect. The significance of variation portions was tested by redundancy analysis with a 200 permutations test (Legendre \& Legendre, 1998). The contribution of each set of variables was significant at $p<0.01$. Both, cross-correlation and variance partitioning were performed using R statistical language (version 2.10.0).

Finally, a conceptual diagram integrating the major results was modelled in Arclnfo 9.3 package for Windows.

\section{Results and discussion}

3.1 Trace element source. The sediment core was primarily composed of mobilised terrestrial inorganic detritus, brought into the lake during thaw and rain events. The stepwise multiple linear regression significantly related $\mathrm{As}, \mathrm{Co}, \mathrm{Cr}, \mathrm{Cu}, \mathrm{Mn}, \mathrm{Ni}, \mathrm{Pb}$ and $\mathrm{Zn}$ with major lithogenic constituents Ti, Fe, Al and/or Li (Figure 2). The metal distribution profiles in the sediment core over time show similar pattern (Figure 3a). This similarity together with TEs relationship with lithogenics clearly demonstrates a common origin, as well as a common mechanism of metal mobilisation i.e. via erosion and burial. This is also supported by a strong relationship between TEs and silt and clay size fractions along the core (Pearson $r=0.34$ to 0.9 ( $p<0.05)$, with finer particles inherently hosting more TEs due to a larger surface area. Redox processes in lake' environment can potentially redistribute metals in bottom sediment, influencing their distribution along the sediment profile. Profile distribution of Fe/Mn- two redox sensitive elements, showed no major shift or trend (Figure S1 e-f). This is reflective of natural Fe-Mn oxide inputs, which often host 


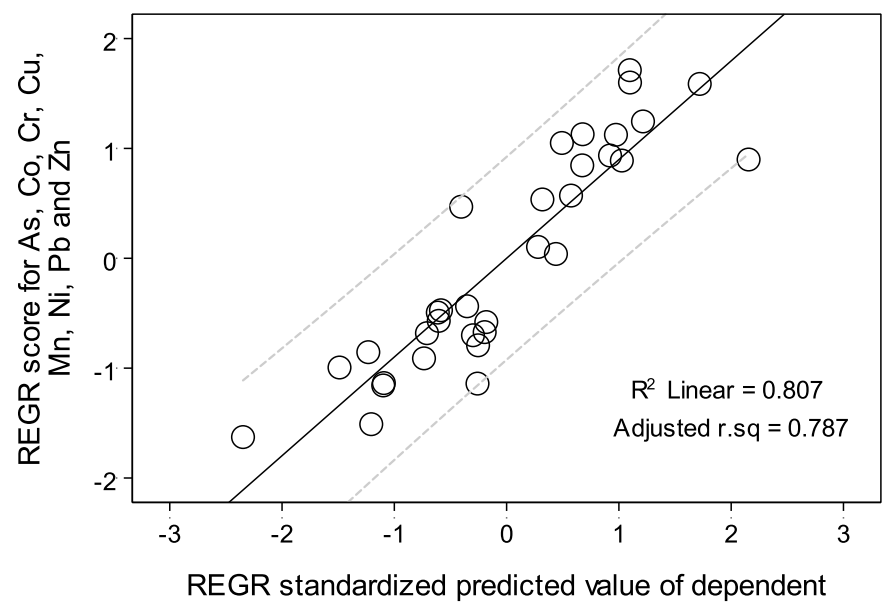

Figure 2. Geogenic control of sediment TEs content. Stepwise multiple linear regression of trace metals (summarised as regression factor scores by principal component analysis) versus their standardised values predicted by major elements $\mathrm{Ti}, \mathrm{Fe}, \mathrm{Al}$ and $\mathrm{Li}$, together with upper and lower $95 \%$ confidence intervals. Significance of the model $p<0.001$.

TEs- hence some connection to TEs is expected. Given the high rate of inflow-outflow of water in/from Bubal reservoir, a low nutrient content (UTE RBE, 2009), largely ice-free winter and low measured organic matter content in its sediment, it is not surprising that no evidence of redox-driven TEs mobilisation along the profile was found (Figure 2). This would have separated the elements into two distinct groups, i.e. redox sensitive (As, Co, $\mathrm{Cr}, \mathrm{Mn}, \mathrm{Ni}$ and $\mathrm{Fe}$ ) and non-sensitive ( $\mathrm{Cu}, \mathrm{Pb}, \mathrm{Zn}, \mathrm{Al}, \mathrm{Li}$ and $\mathrm{Ti}$ ), which was not the case. This means metals accumulated in the core have not been redistributed by redox processes, and thus the core is intact.

The sediment core TE contents display a relatively moderate variability, with CV of 8.7-22.9\% (Table S1), reflecting the extent of the variation in their input from the catchment. Three clearly visible metal peaks observed were at $27-30 \mathrm{~cm}, 18-21 \mathrm{~cm}$ and a relatively broader increase between 3 and $12 \mathrm{~cm}$ depth (Figure 3a). This, points to three major metal input events, corresponding to the estimated periods of 1985-1987, 19911993 and 1997-2003, respectively. Except $\mathrm{Cr}$, all other TEs show increasing trends, from lower values in the 1970 s and the 1980s to higher accumulation in recent years (Figure $3 a$ ), as supported by a significant association of TEs with depth (Pearson $r=0.68, p<$ 0.001). This could, in theory, result from increased atmospheric metal and proton deposition, change in the land cover, and/or climate change driven increased mobilization.

Rain acidity and airborne pollution inputs (including metals) are relatively low in the Pyrenees compared to other European mountain ranges, and they have significantly decreased with the implementation of industrial emission control technologies since the early 1970s (Mosello, 2002; Pacyna et al., 2007). This means acidity input is not likely to 


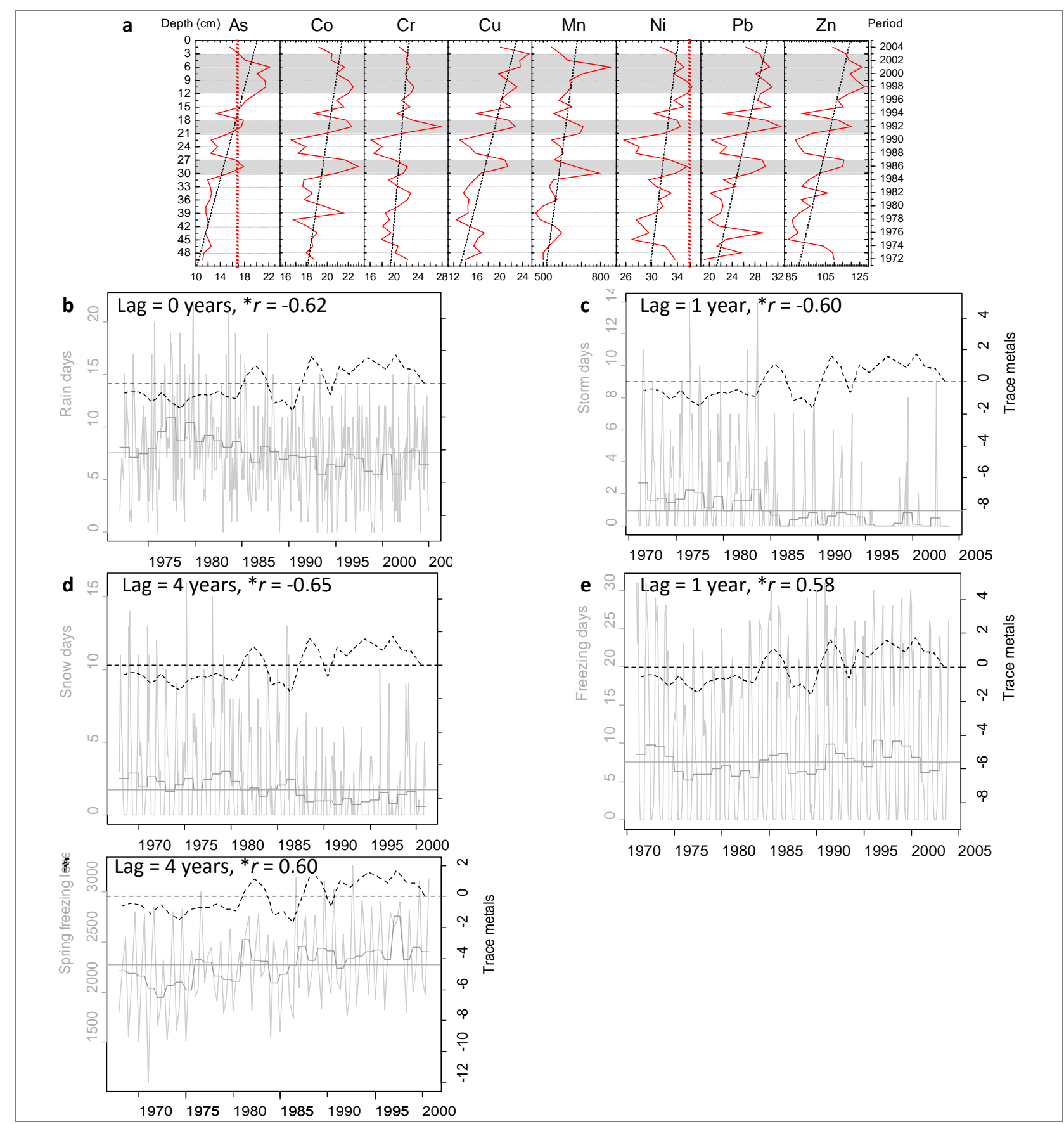

Figure 3. Lake sediment trace metal levels have risen and fallen in step with climate changes during the period 1972-2006. a, Observed variation of TMs $\left(\mathrm{mg} \mathrm{kg}^{-1}\right)$ in bottom sediments of Lake Bubal (Central Pyrenees), with major trends represented by dashed black lines. The metals exhibit clearly visible peaks in concentrations at 27-30, 18-21 and 3-12 cm depths. Vertical (dashed) lines in red represent sediment guide values for the protection of aquatic ecosystem (CCME, 1999). b-f, Sediment TMs (As, Co, Cr, Cu, Mn, Ni, Pb and $\mathrm{Zn}$, summarized as regression factor scores of principal component analysis) trend- black dashed line, against $\mathbf{b}$ - rain days, c- storm days, $\mathbf{d}$ - snow days, e- freezing days and $\mathbf{f}$ - spring freezing level, and their LOESS (locally estimated scatterplot smoothing) fit lines (dark grey line). Horizontal lines are set at means of series. $95 \%$ Pearson correlation significance $\left({ }^{*}\right)$ between TEs and climate variables is drawn after 1,000 permutations test. Climate variables are shifted with respect to TMs on their identified lag response. 

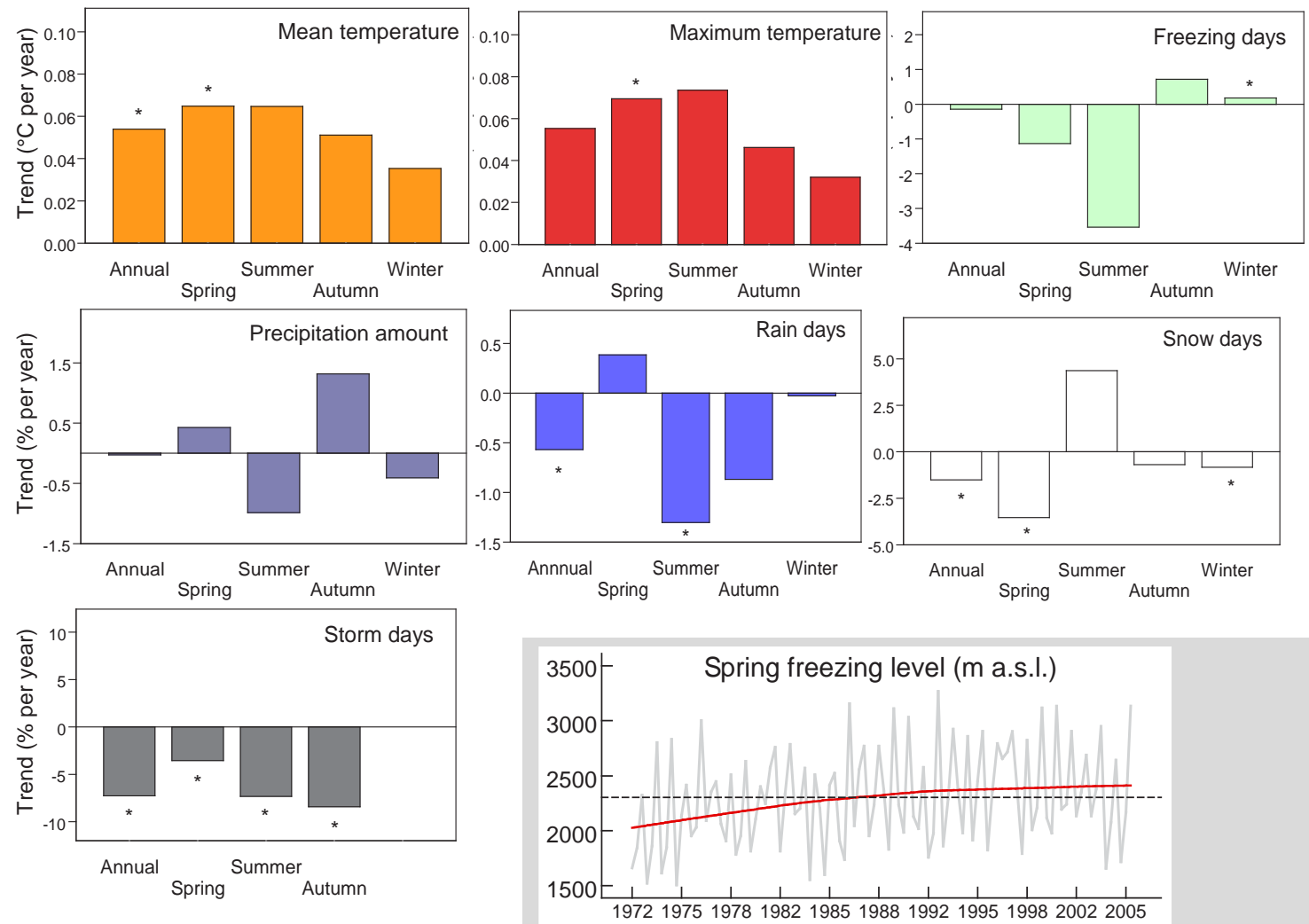

Figure 4. Bubal lake catchment has experienced significant changes in annual and seasonal climate in the period 1972-2006. Long term climate trends are drawn from a locally estimated scatterplot smoothing (LOESS) regression, filter factor $\alpha=1$ span. Trend significance $(* ; p<0.05)$ was given by Mann-Kendall test. Inset plot shows the variability in spring freezing level across the record period (in grey) together with its long term trend (in red) as given by LOESS fit line at $\alpha=1$. The trend was significant at $p<0.05$ (MannKendall test). Horizontal dashed line is at the mean of series.

have increased the mineralisation/ dissolution rates, and significant reductions in atmospheric metal deposition across Europe (Pacyna et al., 2007) cannot be responsible for increasing sediment metal accumulation trends seen here. Catchment vegetation is also not expected to be responsible for TEs mobilisation, as the land cover has not undergone any major changes during the record period. It is thus quite likely that this is mainly an outcome of increased denudation of catchment surfaces driven by changing climate.

Having discounted significant atmospheric contributions and land cover/use, this leaves climate change as the expected driver of TEs mobilisation. To investigate this, we evaluated the relationship between a number of climatic variables and sediment metal contents for the 1972-2004 sedimentation period. 
3.2 Change in catchment's climate. The annual temperatures in Bubal lake catchment showed decadal fluctuations with overall increases between the early $1970 \mathrm{~s}$ and the mid-2000s of about 1.73 and $1.77^{\circ} \mathrm{C}$ for the mean and maximum temperatures, respectively (Figure 4). This is similar to the global temperature rise in mountain regions, and is more than twice compared with the northern hemisphere average (Nogues-Bravo et al., 2007; Piao et al., 2010). The precipitation amount did not change significantly over the studied period; however, the frequencies of rain and snow days decreased by 18.20 and $48.25 \%$, respectively, especially since the mid-1980s (Figure 3b and d and Figure 4). This indicates that precipitation became less frequent but more intense. This obviously means a reduction in permanent stream-flow but increase in temporary runoff and drier soil surfaces. The seasonal changes in the climatic parameters broadly followed the annual trends, with lower frequencies of winter and spring snow days and summer rain days, particularly since the mid-1980s (Figure 4, variability not shown). This reveals a shift in the

climate scenario since the mid-1980s to mildly warmer seasons with drier winters, as given by less snow fall/ accumulation, and a slight change in surface freezing days. The rise in temperature also meant an elevation of the freezing line from about $1944 \mathrm{~m}$ a.s.l. in 1972 to $2489 \mathrm{~m}$ a.s.I. in 2003, with consequential increase in the catchment area remaining uncovered, i.e. below $0{ }^{\circ} \mathrm{C}$ isotherm (Figure 4 and Figure $5 \mathrm{c}$ ).

3.3 Climate-enhanced lithogenic trace element mobilization. The aforementioned changes in temperature, precipitation and freezing line could alter catchment weathering, snow-cover period and surface, water bodies' heat balance and metabolism (White \& Blum, 1995). All these could result in greater transportation of TEs in the catchment either in mineral form or associated to mineral-organic complexes. Spring freezing level, record period, sediment TE contents and freezing days were inversely related to the precipitation variables (Figure $3 b-f$ and Figure 5 ). Variance partition further revealed that the largest portion of variance in sediment metal accumulation was explained by an interaction between the climatic factors. It unveils a rather complex scenario in which it is not possible for a single factor to account for the variability in sediment metal deposition. Instead a pool of factors work in concert to significantly increase metal denudation from exposed mountain geology over the 30 years period, followed by their transport by turbulent runoff into the streams system during storm events/spring thaw and further deposition into the lake bed. A conceptualised example built upon the results (Figure 5c) illustrates that a sharp elevation of spring freezing level (increasingly unfrozen surface, in yellow) and changes in the other climate patterns in the past three decades have the potential to substantially increase TEs release from the lake catchment. 

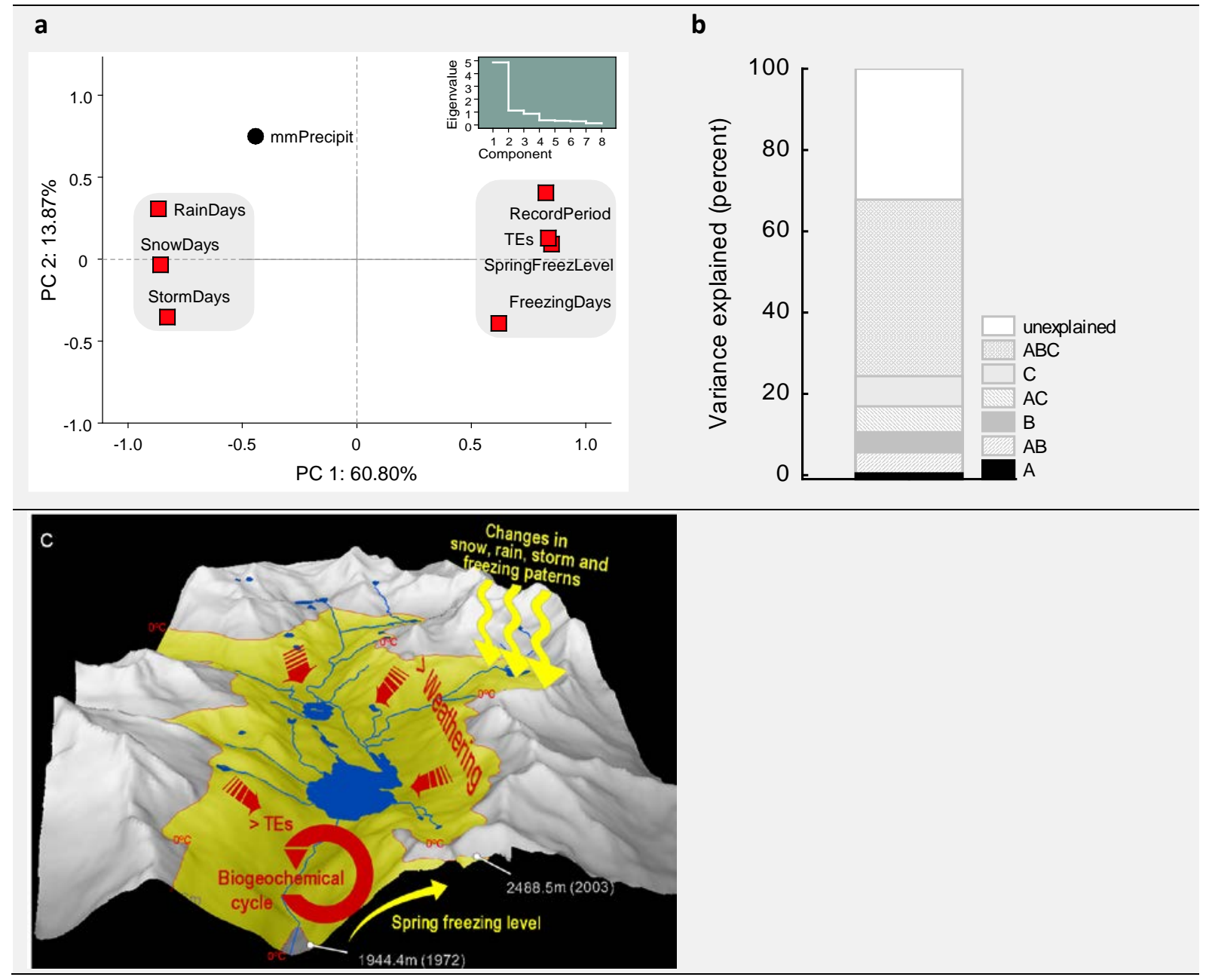

Figure 5. Climate-drivers of increased metal mobilisation. a, Relationship between climate variables (input as LOESS predicted values, 0.1 span), TMs ( $\mathrm{As}, \mathrm{Co}, \mathrm{Cr}, \mathrm{Cu}, \mathrm{Mn}, \mathrm{Ni}, \mathrm{Pb}$ and $\mathrm{Zn}$, summarised as PCA regression factor scores) and record period shown in the projection of PC1- PC2 of principal component analysis. Figures highlight a tight relationship between sediment TEs input, spring freezing level, precipitation and freezing day frequencies, supporting thus the hypothesis of an increased metal mobilisation with climate change. Symbols key: $\mathbf{a}$, elements correlating to PC1; and $\bullet$, element correlating to PC2. b, Variance in sediment trace metal contents over time was partitioned among climate factors. The sets of explanatory variables were: A- exposed surface (spring freezing level and snow days), B- changes in wet-dry period over time (rain days and record period) and $C$ - extreme events (storm days and freezing days) together with their first order $(A B$ and $A C)$ and second order $(A B C)$ interactions. Interaction between climate factors explained most of variation in TEs concentrations in the lake sediments over time. The variances explained by each variable separately were: snow days: $47.5 \%$, spring freezing level: $45.4 \%$, record period: $44.3 \%$, rain days: $36.8 \%$, freezing days: $33.9 \%$ and storm days: $33.8 \%$. These portions were significant at $p<0.01$. c, A conceptualised example illustrating the increased TEs release in catchment environment (Respomuso lake subcatchment at 2130-3058 $\mathrm{m}$ a.s.l., enclosed on a dark grey polygon in Fig. 1) following the sharp elevation of spring freezing level (increasingly unfrozen surface, in yellow) and changes in other climate patterns in the past three decades. The estimates show that great part of the catchment (or above $1944 \mathrm{~m}$ a.s.I.) was snow covered before 1972 but it dramatically decreased in coverage in recent years (yellow area). 
The complexity of the processes involved is further increased by a lag found in TEs peaks in relationship to climate variability (Figure $3 b-f$ ). Given the nature of the weathering processes, a lagged response is naturally expected, as denudation, transport and final burial of sediments are physically time-dependent. Nevertheless, it is implicit that an increase in the number of drier periods (as defined by the decreased frequency of precipitation events) increases weathering and denudation of the catchment slopes (during wet/dry cycles), enhancing the amount of TEs transported and buried into the lakebed sediments. Unexpectedly high metal increment along the core profile is consistent with chemical weathering of catchment's metal sulphides, e.g. pyrites, which during the dry span within the wet-dry cycles oxidise to metal sulphates and oxides. During subsequent wet cycles these metal-rich weathering byproducts can easily be leached (Griethuysen et al., 2005) into the catchment water-bodies, being aided by relatively poorly developed soils on the mountain slopes. The climate change mediated increased mobilization is further supported by the association of major lithogenic elements $\mathrm{Ti}, \mathrm{Fe}, \mathrm{Al}$ and Li with TEs in the sediment (Figure 2).

The reduction in snow-cover, together with the elevation of spring freezing line (increasingly unfrozen surfaces) also appeared to have contributed significantly to enhanced release of TEs, by exposing additional rock/soil surfaces to denudation processes. It has been shown that weathering rates in granitic catchments can increase about one order of magnitude when uncovered mineral surface experiences substantial warming while precipitation volume is constant (White \& Blum, 1995).

Such increases in mineral surface temperatures are possible during spring/summer on the south facing slopes of catchments that remain increasingly snow-uncovered especially when precipitation events have also diminished. In Lake Bubal catchment the drainage of mineral deposits from the surrounding metamorphic belt is the major potential source of TEs (Figure 1). These ores have significant presence of TEs in vein-type mineralization with As content as high as $250 \pm 40 \mathrm{mg} \mathrm{kg}^{-1}$ (Subias, Fanlo \& FernandezNieto, 1993). These As and/or TEs containing sulphides can oxidise relatively rapidly under neutral $\mathrm{pH}$ and, therefore, release As and other elements in the environment at enhanced rates (Davis, 2006), being aided by a relatively high diffusion factor of oxygen in drier surfaces and modified climate patterns. Total precipitation, which is usually ascribed to intensify weathering, however showed no particular influence. This would suggest that changes in precipitation patterns are stronger than the total amount of precipitation in mobilising TEs.

3.4 Potential environmental risk. The incremental metal release with changing climatic pattern raises then the question of potential risks to the environment. Arsenic in the surface sediment layers $(<15 \mathrm{~cm})$ exceeded its safe guide concentration of $17 \mathrm{mg} \mathrm{kg}^{-1}$ for 
the protection of aquatic life (CCME, 1999) (Figure 3a). This is important since As is a priority carcinogenic pollutant ranking first in international hazardous substances lists, and it can be a human safety concern even at background values of $7-18 \mathrm{mg} \mathrm{kg}^{-1}$ (Dani, 2010). Metals in sediments can pose significant and increasing threat to the wider environment if their natural background source is high (CCME, 1999; Dani, 2010). Nickel also reached its safe threshold of $36 \mathrm{mg} \mathrm{kg}^{-1}$ (Dani, 2010) in surface sediments. The elevated As and $\mathrm{Ni}$ in the upper sediment layers are consistent with their general distribution in stream sediments and waters in this catchment, with As values in surface (stream and lake) sediments as high as 161.2 (Zaharescu et al., 2009a; Zaharescu et al., 2009b) and 339.5 (Lavilla et al., 2006) $\mathrm{mg} \mathrm{kg}^{-1}$. Although TEs in Lake Bubal may not cause immediate concern, the evidence of their increased mobilisation and high background levels means climate change could trigger the release of metals from their natural stores. This could lead to potentially detrimental consequences for the ecosystems and beyond, particularly in regions where significant natural metal storage sites experience major climate change.

3.1 Conclusion. We acknowledge that the relationship between climate change and TEs mineralisation/mobilisation and their accumulation is complex and controlled by a multitude of factors. Our results nevertheless demonstrate a clear link between increased TEs accumulation in lakebed sediment and changes in key climate drivers. To clearly determine whether the increased mobilisation of natural metal sources seen herein is an extended and ongoing process warrants further large scale surveys, particularly in sensitive regions characterised by metal-rich geologies.

\section{Acknowledgements}

This work was financially supported by a Félix de Azara award of Huesca Provincial Council, Spain, as well as by University of Vigo, Spain and Kingston University London, UK. The sponsors were not involved in the research or article preparation. We are deeply grateful to the Spanish National Institute of Meteorology in Madrid, Spain for providing climate data, to Mariano Lastra-Valdor, from the University of Vigo, for his substantial support during project execution, as well as to Craig Rasmussen, Joel Cuello and Cody Brown from the University of Arizona for their help with particle size analysis.

\section{Author contributions}

D.G. Zaharescu, C.I. Burghelea and P.Hooda contributed equally to the conceptual development, material analysis and manuscript preparation. V. Polyakov contributed the analysis and interpretation of radiometric samples. A. Palanca-Soler supported sediment analysis and meteorological data acquisition. 


\section{Additional Information}

Competing financial interests: The authors declare no competing financial interests.

\section{References}

Agustí-Panareda A., Thompson R., Livingstone DM. 2000. Reconstructing temperature variations at high elevation lake sites in Europe during the instrumental period. Verhandlungen der Internationalen Vereinigung für Theoretische und Angewandte Limnologie 27:479-483.

Appleby PG. 2000. Radiometric dating of sediment records in European mountain lakes. Journal of Limnology 59:1-14.

Augustsson A., Gallard M-J., Peltola P., Mazier F., Bergback B., Saarinen T. 2013. Effects of land use and climate change on erosion intensity and sediment geochemistry at Lake Lehmilampi, Finland. The Holocene 23:1247-1259.

Bacardit-Penarroya M. 2011. Trace elements biogeochemistry in high mountain lake catchments: identifying anthropogenic versus natural components from the atmospheric contamination legacy in remote natural areas. PhD thesis, University of Girona, Spain.

Beniston M., Diaz HF., Bradley RS. 1997. Climatic change at high elevation sites: an overview. Climatic Change 36:233-251.

Bing H., Wu Y., Zhou J., Li R., Wang J. 2016. Historical trends of anthropogenic metals in Eastern Tibetan Plateau as reconstructed from alpine lake sediments over the last century. Chemosphere 148:211-219. DOI: 10.1016/j.chemosphere.2016.01.042.

Blois JL., McGuire JL., Hadly EA. 2010. Small mammal diversity loss in response to latePleistocene climatic change. Nature 465:771-774. DOI: 10.1038/nature09077.

Bouyoucos GJ. 1962. Hydrometer method improved for making particle size analysis of soils. Agronomy Journal 54:464-465.

Camarero L., Wright RF., Catalan J., Ventura M. 2004. Application of MAGIC to Lake Redó ( Central Pyrenees ): an assessment of the effects of possible climate driven changes in atmospheric precipitation , base cation deposition , and weathering rates on lake water chemistry. Journal of Limnology 63:123-132.

Camarero L., Catalan J. 1993. Chemistry of bulk precipitation in the central and Eastern Pyrenees, Northeast Spain. Atmospheric Environment 27:83-94. 
(CCME) Canadian Council of Ministers of the Environment. 1999. Canadian Environmental Quality Guidelines. Chapter 6, Canadian Sediment Quality Guidelines for the Protection of Aquatic Life. Winnipeg.Charlet L., Polya DA. 2004. Arsenic in shallow, reducing groundwaters in Southern Asia: an environmental health disaster. Elements 2:91-96.

Dani SU. 2010. Arsenic for the fool: An exponential connection. Science of the Total Environment 408:1842-1846. DOI: 10.1016/j.scitotenv.2010.01.027.

Davis A et al. 2006. The nexus between groundwater modelling pit lake chemogenesis and ecological risk from arsenic in the Getchell Main Pit, Nevada, U.S.A. Chemical Geology 228:175-196.

Dessens J., Bucher A. 1997. A critical examination of the precipitation records at the Pic du Midi observatory, Pyrenees, France. Climatic Change 36:345-353.

Diaz HF., Bradley RS. 1997. Temperature variations during the last century at high elevation sites. Climatic Change 36:253-279.

Garrido SE. 2002. The thermalisme of the batholite of Panticosa (Huesca): hydrochemistry characteristics and relationship with the hydrothermal system of Cauterrets-Panticosa granitic massif (Spain-France). In: Proceedings of the XI International Congress on Industry, Mining and Metallurgy. Zaragoza, Spain, 1-20.

Geiger R. 1965. The Climate Near the Ground. Harvard University Press.

Griethuysen C Van., Luitwieler M., Joziasse J., Koelmans AA. 2005. Temporal variation of trace metal geochemistry in floodplain lake sediment subject to dynamic hydrological conditions. Environmental Pollution 137:281-294. DOI: 10.1016/j.envpol.2005.01.023.

Kotarba A., Okas E., Wachniew PAW. 2002. Pb dating of young holocene sediments in high-mountains lakes of the Tatra mountains. Geochronometria 21:73-78.

Lavilla I., Filgueiras A V., Valverde F., Millos J., Palanca A., Bendicho C. 2006. Depth profile of trace elements in a sediment core of a high-altitude lake deposit at the Pyrenees, Spain. Water, Air and Soil Pollution 172:273-293. DOI: 10.1007/s11270006-9079-0.

Legendre P., Legendre L. 1998. Numerical ecology. Elsevier Science BV.

Limnos. 1996. Diagnóstico y gestión ambiental de embalses en el ámbito de la cuenca hidrográfica del Ebro. Embalse de Búbal [in Spanish].

Macdonald RW., Harner T., Fyfe J. 2005. Recent climate change in the Arctic and its impact on contaminant pathways and interpretation of temporal trend data. Science of the Total Environment 342:5-86. DOI: 10.1016/j.scitotenv.2004.12.059. 
Mecray EL., King JW., Appleby PG., Hunt A. 2001. Historical trace metal accumulation in the sediments of an urbanized region of the lake Champlain watershed, Bulington, Vermont. Water, Air and Soil Pollution 125:201-230.

Michaelson J. 1987. Cross-validation in statistical climate forecast models. Journal of Climate and Applied Meteorology 26:1589-1600.

Michelutti N., Simonetti A., Briner JP., Funder S., Creaser RA., Wolfe AP. 2009. Temporal trends of pollution $\mathrm{Pb}$ and other metals in east-central Baf fi $\mathrm{n}$ Island inferred from lake sediment geochemistry. Science of the Total Environment 407:5653-5662. DOI: 10.1016/j.scitotenv.2009.07.004.

Mosello R et al. 2002. Trends in the water chemistry of high altitude lakes in Europe. Water, Air and Soil Pollution 2:75-89.

(NASA) National Aeronautics and Space Administration., (JPL) Jet Propulsion Laboratory., Agency NI and M. 2003.PIA03395: World in Mercator Projection, Shaded Relief and Colored Height. Available at http://photojournal.jpl.nasa.gov/catalog/PIA03395 (accessed November 2, 2015).

Nogues-Bravo D., Araujo MB., Errea MP., Martinez-Rica JP. 2007. Exposure of global mountain systems to climate warming during the 21st Century. Global Environmental Change 17:420-428. DOI: 10.1016/j.gloenvcha.2006.11.007.

Outridge PM., Stern GA., Hamilton PB., Percival JB., McNeely R., Lockhart WL. 2005. Trace metal profiles in the varved sediment of an Arctic lake. Geochimica et Cosmochimica Acta 69:4881-4894. DOI: 10.1016/j.gca.2005.06.009.

Pacyna E., Pacyna J., J F., Strzelecka-Jastrzab E., S H., Panasiuk D., Nitter S., Pregger T., Pfeiffer H., Friedrich R. 2007. Current and future emissions of selected heavy metals to the atmosphere from anthropogenic sources in Europe. Atmospheric Environment 41:8557-8556.

Peterson TC., Easterling DR., Karl TR., Groisman P., Nicholls N., Plummer N., Torok S., Auer I., Boehm R., Gullett D., Vincent L., Heino R., Tuomenvirta H., Mestre O., Salinger J., Hanssen-bauer I., Alexandersson H., Jones P., Parker D. 1998. Homogeneity adjustments of in situ atmospheric climate data: A review. International Journal of Climatology 18:1493-1517.

Piao S., Ciais P., Huang Y., Shen Z., Peng S., Li J., Zhou L., Liu H., Ma Y., Ding Y., Friedlingstein P., Liu C., Tan K., Yu Y., Zhang T., Fang J. 2010. The impacts of climate change on water resources and agriculture in China. Nature 467:43-51. DOI: 10.1038/nature09364.

Psenner R., Schmtdt R. 1992. Climate driven pH control of remote alpine lakes and effects of acid deposition. Nature 356:781-783.

Rockström J et al. 2009. A safe operating space for humanity. Nature 461:472-475. 
Rosenblüth B., Fuenzalida HA., Aceituno P. 1997. Recent temperature variations in southern South America. International Journal of Climatology 17:67-85.

Rowell D. 1994. Soil science. Methods and Applications. Addison Wesley Longman Limited.

Santschi PH., Nixon S., Pilson M., Hunt C. 1984. Accumulation of sediments, trace metals (lead, copper) and total hydrocarbons in Narragansett Bay, Rhode Island. Estuarine, Coastal and Shelf Science 19:427-449.

Savage KS., Tingle TN., Day PAO., Waychunas A., Bird DK. 2000. Arsenic speciation in pyrite and secondary weathering phases , Mother Lode Gold District , Tuolumne County , California. Applied Geochemistry 15:1219-1244.

Stallard RF., Edmond JM. 1983. Geochemistry of the Amazon 2. The influence of geology and weathering environment on the dissolved load. Journal of Geophysical Research 88:9671-9688.

Subias I. 1993. Yacimientos Hidrotermales de Pb-Zn-F del Área de Sallent de Gállego Panticosa, Pirineos Occidentales (Huesca)[in spanish]. PhD thesis, University of Zaragoza, Spain.

Subias I., Fanlo I., Fernandez-Nieto C. 1993. Las rnineralizaciones filonianas de F-Zn-Pb de Las Marmoleras (Pirineo occidental , prov. Huesca): caracterización geológica, mineralógica y geoquímica [in Spanish]. Acta Geologica Hispanica 28:49-61.

Subias I., Fernandez-Neto C. 1995. Hydrothermal events in the Valle de Tena ( Spanish Western Pyrenees ) as evidenced by fluid inclusions and trace-element distribution from fluorite deposits. Chemical Geology 124:267-282.

Subias I., Moritz R., Fernandez-Nieto C. 1998. Isotopic composition of strontium in the Valle de Tena (Spanish Central Pyrenees) Fluorite deposits : relevance for the source of elements and genetic significance. Mineralium Deposita:416-424.

Thies H., Nickus U., Mair V., Tessadri R., Tait D., Thaler B., Psenner R. 2007. Unexpected Response of High Alpine Lake Waters to Climate Warming. Environmental Science \& Technology 41:7424-7429.

(USEPA) US Environmental Protection Agency. 1999. SW-846 Reference Methodology: Method 3050B - Standard Operating Procedure for the Digestion of Soil/Sediment Samples Using a Hotplate/Beaker Digestion Technique. Chicago, U.S.A.

(USEPA) US Environmental Protection Agency. 2007. SW-846 Reference Methodology, Method 3051A: Microwave Assisted Acid Digestion of Sediments, Sludges, Soils, and Oils.

(UTE RBE) UTE Red Biológica Ebro. 2009. Informe final del embalse de Búbal. Año 2009 [in Spanish]. Madrid. 
Valero-Garces BL., Navas A., Machın J., Walling D. 1999. Sediment sources and siltation in mountain reservoirs: a case study from the Central Spanish Pyrenees. Geomorphology 28:23-41.

Walling DE., He Q., Appleby PG. 2002. Conversion Models for Use in Soil-Erosion, SoilRedistribution and Sedimentation Investigations. In: Zapata F, ed. Handbook for the Assessment of Soil Erosion and Sedimentation Using Environmental Radionuclides. Dordrecht: Kluwer Academic Publishers, 111-164. DOI: 10.1007/0-306-48054-9.

White AF., Blum AE. 1995. Effects of climate on chemical weathering in watersheds. Geochimica et Cosmochimica Acta 59:1729-1747.

Williamson CE., Saros JE., Vincent WF., Smol JP. 2009. Lakes and reservoirs as sentinels , integrators , and regulators of climate change. Limnology and Oceanography 54:22732282.

Yang ZR., Graham EY., Luons WB. 2003. Geochemistry of Pyramid Lake sediments: influence of anthropogenic activities and climatic variations within the basin. Environmental Geology 43:688-697.

Zaharescu DG., Hooda PS., Soler AP., Fernandez J., Burghelea CI. 2009a. Trace metals and their source in the catchment of the high altitude Lake Respomuso, Central Pyrenees. Science of The Total Environment 407:3546-53. DOI: 10.1016/j.scitotenv.2009.02.026.

Zaharescu DG., Hooda PS., Fernandez J., Soler AP., Burghelea CI. 2009b. On the arsenic source mobilisation and its natural enrichment in the sediments of a high mountain cirque in the Pyrenees. Journal of Environmental Monitoring 11:1973-81. DOI: 10.1039/b912432b. 


\section{SUPPLEMENTARY INFORMATION}

\section{Climate change enhances the mobilisation of naturally occurring metals in high altitude environments}

Hydrology and climate. The sediment input to lakes in the catchment is primarily expected during spring melts and precipitation events and to a lesser extent by the permanent tributaries during drier inter-periods. The reservoir's basin follows the relatively steep slopes of the valley with the sedimentation taking place mainly in its deepest parts. The average depth is $22.8 \mathrm{~m}$ with $72.7 \mathrm{~m}$ at its deepest point (UTE RBE, 2009).

Snow-thaw and rainwater comprise the major water input, and no significant industrial or extensive agricultural activities exist/existed in the area. There may be some localised emissions from tourism activities in the catchment. However, local aerial contribution during peak tourism season is low (Zaharescu et al., 2009). The economy in the valley is mostly tourism dependent. Vegetation cover and land use have not changed markedly over the last decades.

Analysis for trace, major elements and organic matter contents. Quality control protocol for trace metal (As, $\mathrm{Cd}$. $\mathrm{Co}, \mathrm{Cr}, \mathrm{Cu}, \mathrm{Mn}, \mathrm{Ni}, \mathrm{Pb}$ and $\mathrm{Zn}$ ) analysis included reagent blanks, certified reference materials and sample duplicates. The ICP-MS was highly sensitive for the elements in terms of detection limit and reproducibility. Overall the analysis was highly reliable, with \% relative standard deviation (RSD) between replicates and between measurements of the same sample being $<5 \%$. The RSD for Cd was about $25 \%$, which is not uncommon at elemental levels close to the detection limit; nonetheless it was not considered satisfactory enough and was therefore removed from further analysis. The percentage recoveries of the analysed elements were generally consistent with that specified for USEPA Method 3050B used (USEPA, 1999).

Major elements (Ti, Fe, Al and Li) were determined following USEPA Method 3051A for ICP-OES (USEPA, 2007). Briefly, this involved ashing a portion (0.1g) of dried sediment at $550{ }^{\circ} \mathrm{C}$ for $10 \mathrm{~h}$ to remove organic matter before being digested by using a mixture of 
concentrated $\mathrm{HCl}, \mathrm{HNO}_{3}$ and perchloric acid $\left(\mathrm{HClO}_{4}\right)$. The samples were subjected to ultrasound assisted digestion at $60{ }^{\circ} \mathrm{C}$ for $15 \mathrm{~min}$, then kept on $125{ }^{\circ} \mathrm{C}$ sand bed until nearly complete evaporation. A certified reference material from the National Water Research Institute of Canada (CRM WQB3), procedural blank and three samples were analysed in triplicate to optimize the accuracy, reproducibility and recovery rate of the extraction procedure. After digestion, samples were filtered through Whatman filter 541 and made up to $50 \mathrm{ml}$ with ultrapure water. Overall, analysis of the major elements was highly reliable in terms of precision and accuracy as per the method used. PTF Teflon beakers were used throughout the analyses. All reagents were ultra-pure Aristar grade. Stock standard solutions were Merck Certificate AA standards. Milli-Q water was used in all samples, dilutions and standard solutions, as appropriate. 


\section{Supplementary tables}

Table S1. Variability in trace and major (represented on grey background) element contents ( $\mathrm{mg} \mathrm{kg}^{-1} \mathrm{dry}$ weight) in the $<0.25 \mathrm{~mm}$ sediment fraction of Lake Bubal core.

\begin{tabular}{lllllllllllll}
\hline & As & Co & $\mathrm{Cr}$ & $\mathrm{Cu}$ & $\mathrm{Mn}$ & $\mathrm{Ni}$ & $\mathrm{Pb}$ & $\mathrm{Zn}$ & $\mathrm{Al}$ & $\mathrm{Li}$ & $\mathrm{Fe}$ & $\mathrm{Ti}$ \\
\hline Min. & 11.1 & 16.6 & 16.2 & 12.4 & 460.6 & 25.8 & 19.1 & 83.2 & 13439.0 & 62.0 & 33411.2 & 11.2 \\
Max. & 22.2 & 23.0 & 27.8 & 25.1 & 853.4 & 36.3 & 32.5 & 127.9 & 27574.0 & 93.0 & 45170.0 & 42.9 \\
Mean & 15.1 & 19.8 & 20.9 & 18.0 & 596.8 & 32.0 & 25.7 & 104.5 & 19050.5 & 78.1 & 39530.8 & 23.9 \\
SD & 3.5 & 1.9 & 2.3 & 3.7 & 86.3 & 2.8 & 4.0 & 13.6 & 3280.8 & 8.2 & 3273.5 & 9.3 \\
CV(\%) & 22.9 & 9.4 & 10.9 & 20.3 & 14.5 & 8.7 & 15.5 & 13.1 & 17.2 & 10.5 & 8.3 & 38.9 \\
\hline
\end{tabular}




\section{Supplementary figures}
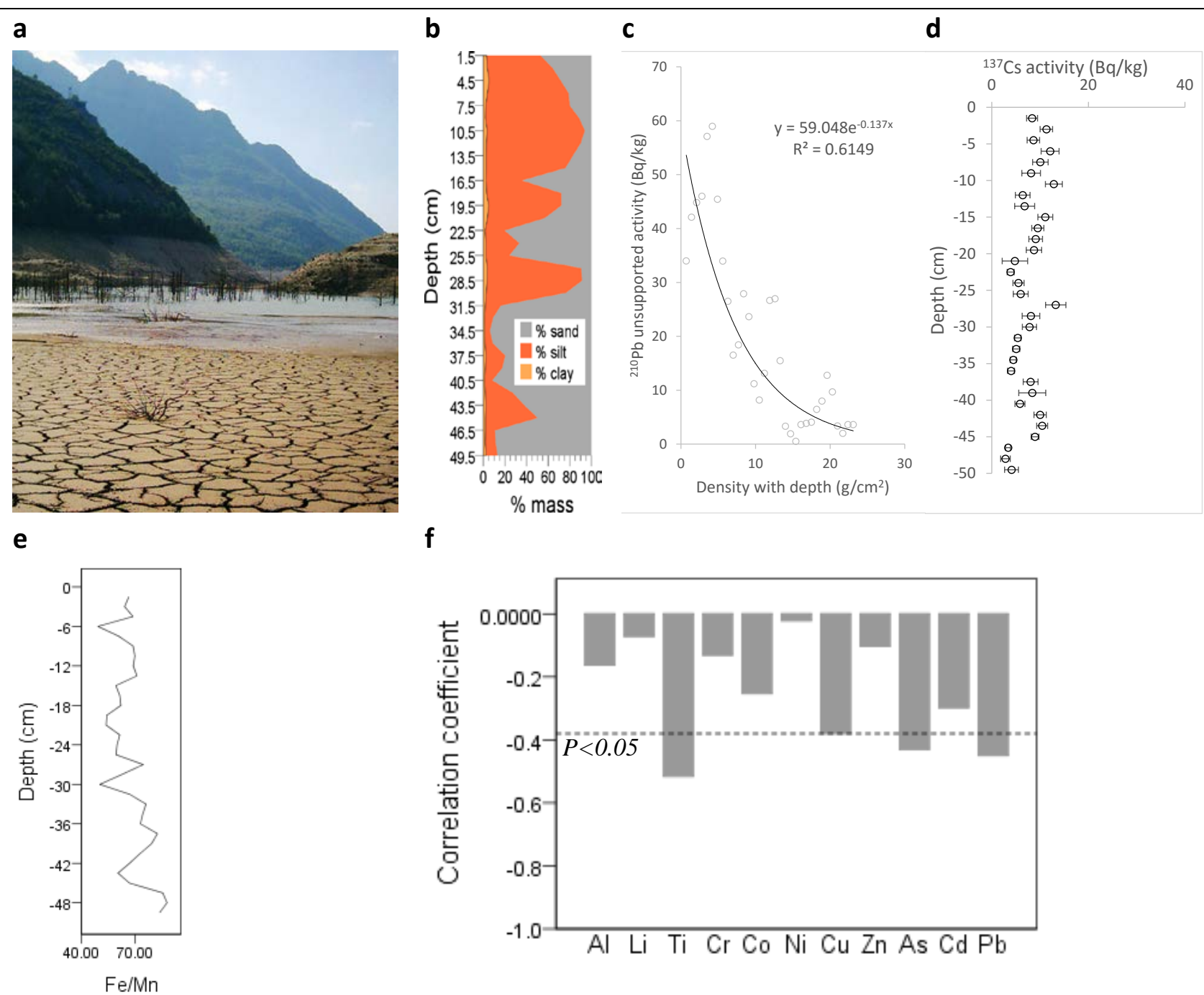

Figure S1. Sediment core characteristics in Lake Bubal. (a) View towards downstream, from sampling site (taken August 2005). (b) Grain size distributions of sand (250-63 $\mu \mathrm{m})$, silt (63-4 $\mu \mathrm{m}$ ) and clay $(<4 \mu \mathrm{m})$; (c) and (d) Fallout radionuclides ${ }^{210} \mathrm{~Pb}$ and ${ }^{137} \mathrm{Cs}$, together with (e) redox-sensitive $\mathrm{Fe} / \mathrm{Mn}$ and (f) its correlation with metal content. These profile distribution patterns are consistent to natural variability in sediment deposition and little evidence of post-depositional disturbance and redox redistribution of elements in the core. 


\section{Supplementary references}

(USEPA) US Environmental Protection Agency (2007) SW-846 Reference Methodology, Method 3051A: Microwave Assisted Acid Digestion of Sediments, Sludges, Soils, and Oils.,

(USEPA) US Environmental Protection Agency (1999) SW-846 Reference Methodology: Method 3050B - Standard Operating Procedure for the Digestion of Soil/Sediment Samples Using a Hotplate/Beaker Digestion Technique., Chicago, U.S.A.

(UTE RBE) UTE Red Biológica Ebro (2009) Informe final del embalse de Búbal. Año 2009 [in Spanish]., Madrid. Available at:

http://195.55.247.234/webcalidad/estudios/embalses/2009embalsesbio/2009_bubal .pdf [Accessed September 18, 2014].

Zaharescu D. G., Hooda P. S., Soler A. P., Fernandez J. and Burghelea C. I. (2009) Trace metals and their source in the catchment of the high altitude Lake Respomuso, Central Pyrenees. Science of the Total Environment: 407, 3546-53. Available at: http://www.ncbi.nlm.nih.gov/pubmed/19275955. 